\title{
RENAL FAILURE IN LAENNEC'S CIRRHOSIS. II. SIMULTANEOUS DETERMINATION OF CARDIAC OUTPUT AND RENAL HEMODYNAMICS *
}

\author{
By RUBEN G. LANCESTREMERE, † PAUL L. DAVIDSON, LAURENCE E. EARLEY, \\ FREDERICK J. O'BRIEN, AND SOLOMON PAPPER $\ddagger$ \\ (From the Medical Service and the Research Laboratory, Boston VA Hospital; the Depart- \\ ments of Medicine, Boston University and Tufts University Schools of Medicine, Boston, \\ Mass.; and the Medical College of Virginia, Richmond, Va.)
}

(Submitted for publication May 12, 1962; accepted June 28, 1962)

A number of observations in patients with Laennec's cirrhosis dying with renal failure-one of the conditions sometimes included in the term "hepatorenal syndrome"-suggest that the observed oliguria and nitrogen retention may be secondary to impaired renal perfusion rather than to any lesion of the renal parenchyma. First, renal failure may develop with great rapidity. In several instances, normal glomerular filtration rate (GFR) had been demonstrated months, weeks, and even days before the development of renal failure (1). Second, renal failure may occur in patients with cirrhosis after mild gastrointestinal bleeding, not severe enough to produce significant change in hematocrit, or after abdominal paracentesis, even when only five liters of fluid are removed (1-3). Minimal bleeding and paracentesis both may result in a decrease in the effective blood volume $(1,4)$. A third observation suggesting a circulatory mechanism of renal failure in cirrhosis is the modest reduction in systemic blood pressure that almost always accompanies the development of renal failure (1). Fourth, the concentration of the urine is generally well maintained early in the course of renal failure and may remain up to three times the concentration of plasma until death (1). Fifth, the concentration of sodium in the urine is low, generally less than

\footnotetext{
* Supported in part by research grant H-5162 from the National Heart Institute, by grant $380-\mathrm{F}$ from the Massachusetts Heart Association, and by the Roanoke Valley Heart Association; presented in part at the 16th Annual Meeting of the Southern Society for Clinical Research, January 19, 1962.

$\dagger$ Work done during tenure of research fellowships of the University of Buenos Aires, Argentina, and of the American Heart Association.

$\ddagger$ Present address: University of New Mexico School of Medicine, Albuquerque, N. Mex.
}

$10 \mathrm{mEq}$ per L (5), an observation consistent with decreased renal perfusion (6), and in contrast to that in the urine in acute tubular necrosis, where the concentration of sodium is usually higher than $60 \mathrm{mEq}$ per L (7). Sixth, some patients with cirrhosis in renal failure respond to the administration of certain pressor drugs with an increase in renal excretion of total solutes, sodium and potassium as well as a larger volume of more dilute urine (8). Finally, the histologic appearance of the kidney fails to show any consistent lesion of proved functional significance $(1,9)$.

In view of these observations it was considered desirable to determine cardiac output ( $\mathrm{CO}$ ) and renal hemodynamics simultaneously in patients with decompensated cirrhosis and renal failure.

The study demonstrates that the reduced renal hemodynamics observed in certain patients with Laennec's cirrhosis cannot be attributed to a low CO.

\section{METHODS}

Studies were performed in seven male patients with Laennec's cirrhosis with clearances of inulin $\left(\mathrm{C}_{\mathrm{IN}}\right)$ or endogenous creatinine $\left(\mathrm{C}_{\mathrm{CR}}\right)$ less than $60 \mathrm{ml}$ per minute. In addition, thirteen patients, twelve male and one female (I.W.), with decompensated cirrhosis and $\mathrm{C}_{\mathrm{IN}}$ or $\mathrm{C}_{\mathrm{CR}}$ greater than $70 \mathrm{ml}$ per minute were studied. One patient, W.F., was studied when $\mathrm{C}_{\mathrm{IN}}$ was normal and on a subsequent occasion when he had developed renal failure. All patients had a history of alcoholism. All had marked ascites, and many had edema of the legs. The diagnosis of cirrhosis was made on the basis of clinical and laboratory findings, and in some instances the diagnosis was confirmed by autopsy. In no patient was there evidence of antecedent renal disease, or any apparent cause, other than cirrhosis, of acute renal disease. In addition, there was no evidence of heart disease.

Patients were studied in the morning hours, at rest, in the recumbent position with a pillow under the head, and with an indwelling catheter placed in the bladder. 
A water load of 20 to $25 \mathrm{ml}$ per $\mathrm{kg}$ of body weight was given either by mouth as tap water, or intravenously as 4 per cent hexose in water. The water lost as urine or insensibly during the study was replaced either orally or intravenously. After the urine flow became stable, $\mathrm{C}_{\mathrm{IN}}$ or $\mathrm{C}_{\mathrm{CR}}$ and clearance of para-aminohippurate $\left(\mathrm{C}_{\mathrm{PAH}}\right)$ were determined according to standard procedure (10). Immediately thereafter, CO was determined with a dilution technique (11) using as an indicator $5 \mathrm{mg}$ of Evans blue dye, T-1824, or $5 \mu \mathrm{c}$ of radio-iodinated human serum albumin, RISA. Multiple samples of blood were obtained from an indwelling Cournand needle placed in the brachial or femoral arteries opposite the site of the injection. In Patient I.W., cardiac output was determined by the direct Fick method. Neither the results of the renal clearances nor the results of $\mathrm{CO}$ were corrected for body surface area because of the presence of marked ascites (12). Creatinine was determined in urine by the Peters modification of the Folin method (13) and in serum by the method of Hare (14). Serum and urine were analyzed for inulin by the method of Young and Raisz (15), and for para-aminohippurate by the method of Goldring and Chasis (16). Evans blue was measured in a Beckman DU spectrophotometer, and radio-iodinated human serum albumin with a well scintillation counter.

\section{RESULTS}

Patients with $C_{I N}$ or $C_{C R}$ less than $60 \mathrm{ml}$ per minute $($ Group $A)$. The concentration of bilirubin in the serum ranged from 1.6 to $32.8 \mathrm{mg}$ per $100 \mathrm{ml}$, and systemic blood pressure from $90 / 60$ to $150 / 80 \mathrm{~mm} \mathrm{Hg}$ (Table I, Group A). The hematocrit was low in all instances. $\mathrm{C}_{\mathrm{IN}}$ or $\mathrm{C}_{\mathrm{CR}}$ were between 2 and $57 \mathrm{ml}$ per minute, $\mathrm{C}_{\mathrm{PAH}}$ between 8 and $352 \mathrm{ml}$ per minute, and the effective renal blood flow (ERBF), calculated as $\mathrm{C}_{\mathrm{PAH}} /$ 1 - hematocrit, between 12 and $451 \mathrm{ml}$ per minute. The filtration fraction $(\mathrm{FF}), \mathrm{C}_{\mathrm{IN}} / \mathrm{C}_{\mathrm{PAH}}$, ranged from 12 to 25 per cent. $\mathrm{CO}$ was found to range from 5.4 to $9.9 \mathrm{~L}$ per minute. In all patients except W.G., CO was greater than $7.0 \mathrm{~L}$ per minute, and in three cases was greater than 9.0 L per minute. As a consequence of this elevated $\mathrm{CO}$ and the reduced $\mathrm{ERBF}$, the renal fraction of the cardiac output (RFCO), calculated as $\mathrm{ERBF} / \mathrm{CO}$, was low, ranging between 0.1 and 7.5 per cent.

TABLE I

Cardiac output and renal hemodynamics in patients with decompensated Laennec's cirrhosis*

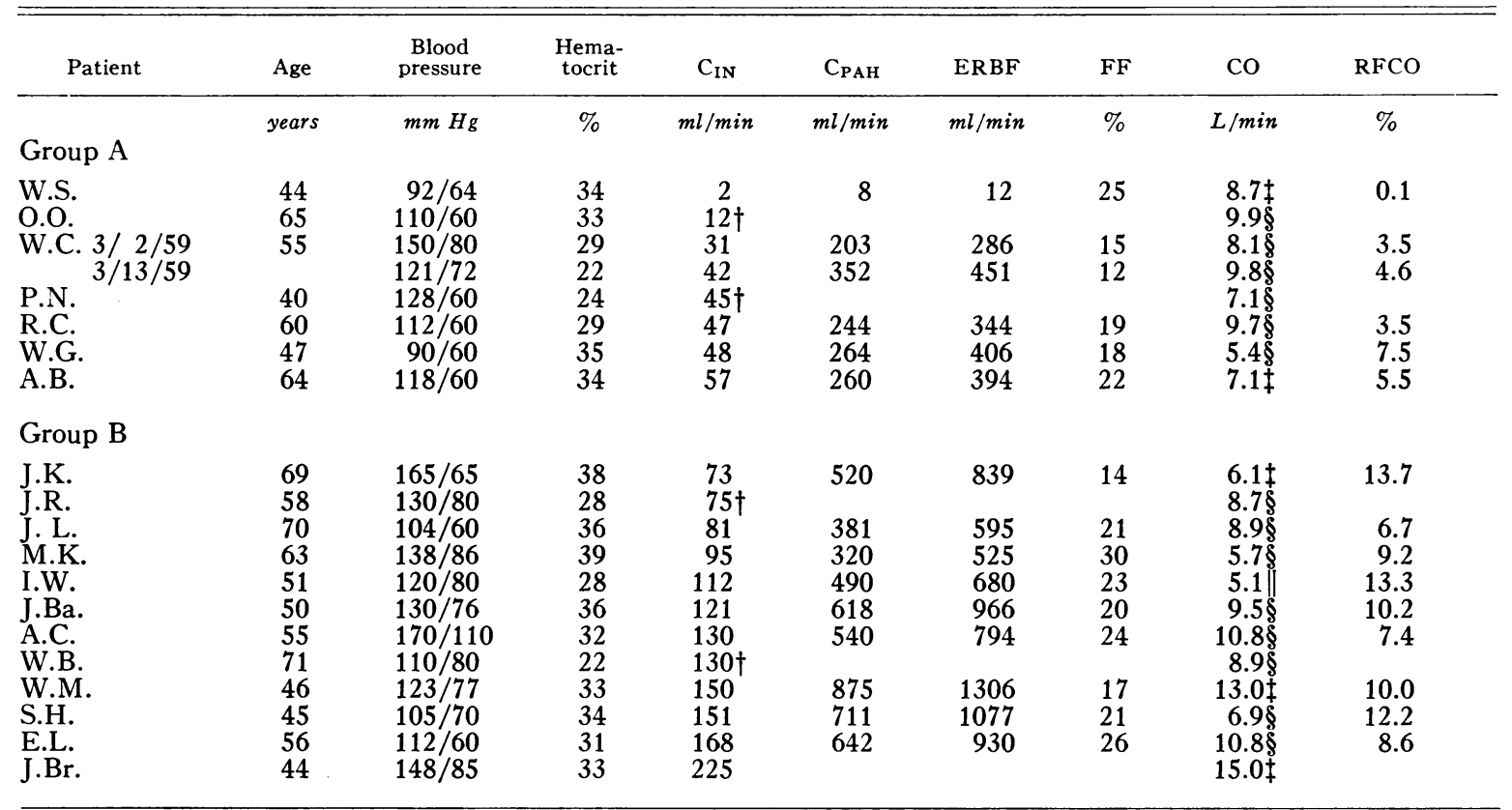

* Abbreviations: $\mathrm{C}_{\mathrm{IN}}=$ inulin clearance, $\mathrm{C}_{\mathrm{PAH}}=$ para-aminohippurate clearance, $\mathrm{ERBF}=$ effective renal blood flow, calculated as $\left(\mathrm{C}_{\mathrm{PAH}} / 1\right.$-hematocrit $), \mathrm{FF}=$ filtration fraction $\left(\mathrm{C}_{\mathrm{IN}} / \mathrm{C}_{\mathrm{PAH}}\right), \mathrm{CO}=$ cardiac output, and $\mathrm{RFCO}=$ renal fraction of cardiac output $(\mathrm{ERBF} / \mathrm{CO})$.

$\dagger$ Endogenous creatinine clearance.

$\ddagger$ With radio-iodinated human serum albumin, RISA.

With Evans blue dye, T-1824.

II By direct Fick method. 


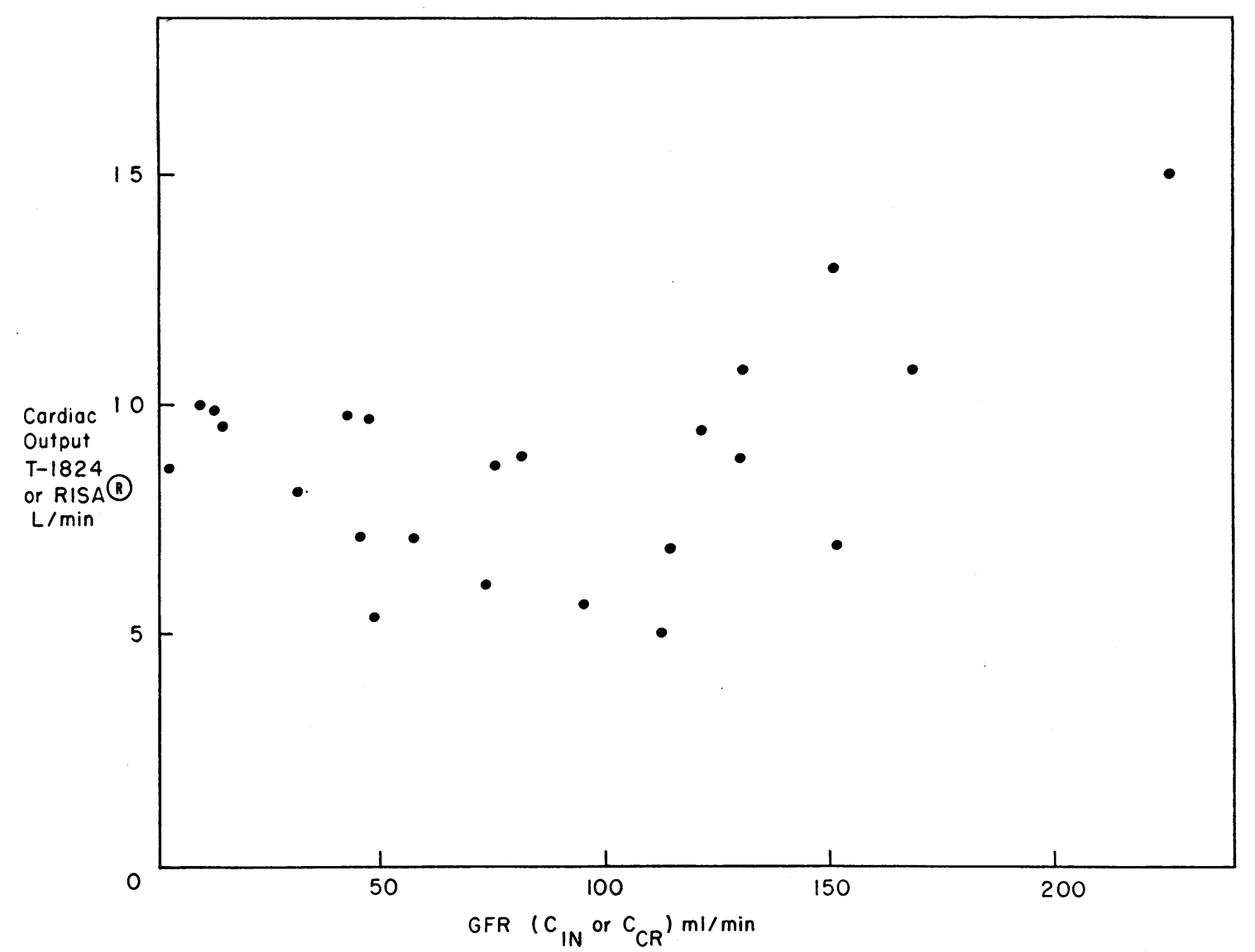

Fig. 1. Cardiac output and glomerular filtration Rate (GFR) in Patients with decompensated Laennec's CIRRHOSIS. Note the coexistence of reduced inulin $\left(C_{I N}\right)$ or creatinine $\left(C_{C_{R}}\right)$ clearances with an elevated cardiac output.

Thus these patients, with marked reduction in renal hemodynamics, in general had an elevated $\mathrm{CO}$ (Figures 1 and 2).

Patients with $C_{I N}$ or $C_{C R}$ greater than $70 \mathrm{ml}$ per minute (Group B). The concentration of bilirubin in the serum ranged from 0.2 to $12.0 \mathrm{mg}$ per $100 \mathrm{ml}$, and systemic blood pressure from $104 / 60$ to $170 / 110 \mathrm{~mm} \mathrm{Hg}$ (Table I, Group B).
The hematocrit was comparable to that of the previous group. $\mathrm{C}_{\mathrm{IN}}$ or $\mathrm{C}_{\mathrm{CR}}$ were between 73 and $225 \mathrm{ml}$ per minute, $\mathrm{C}_{\mathbf{P A B}}$ between 320 and $875 \mathrm{ml}$ per minute, the calculated ERBF between 525 and $1306 \mathrm{ml}$ per minute, and FF between 17 and $30 \%$. Only four patients of this group had a CO lower than $7.0 \mathrm{~L}$ per minute, whereas five had CO greater than $9.0 \mathrm{~L}$ per minute. The calculated

TABLE II

Changes in cardiac output and renal hemodynamics in W.F., a 53-year-old man with decompensated Laennec's cirrhosis*'

\begin{tabular}{rcccccccc}
\hline \hline Date & $\begin{array}{c}\text { Blood } \\
\text { pressure }\end{array}$ & $\begin{array}{c}\text { Hema- } \\
\text { tocrit }\end{array}$ & C C IN & C CAH & ERBF & FF & CO & RFCO \\
\hline & $m m H g$ & $\%$ & $m l / m i n$ & $\operatorname{ml} / \min$ & $\operatorname{ml} / \min$ & $\%$ & $L / \min$ & $\%$ \\
$10 / 24 / 58$ & $110 / 70$ & 31 & 114 & 417 & 604 & 27 & 6.9 & 8.8 \\
$5 / 22 / 59$ & $100 / 58$ & 37 & 9 & 40 & 63 & 22 & 10.0 & 0.6 \\
$6 / 4 / 59$ & $100 / 42$ & 34 & 14 & 43 & 65 & 33 & 9.5 & 0.7 \\
\hline
\end{tabular}

* Abbreviations as in Table I. 


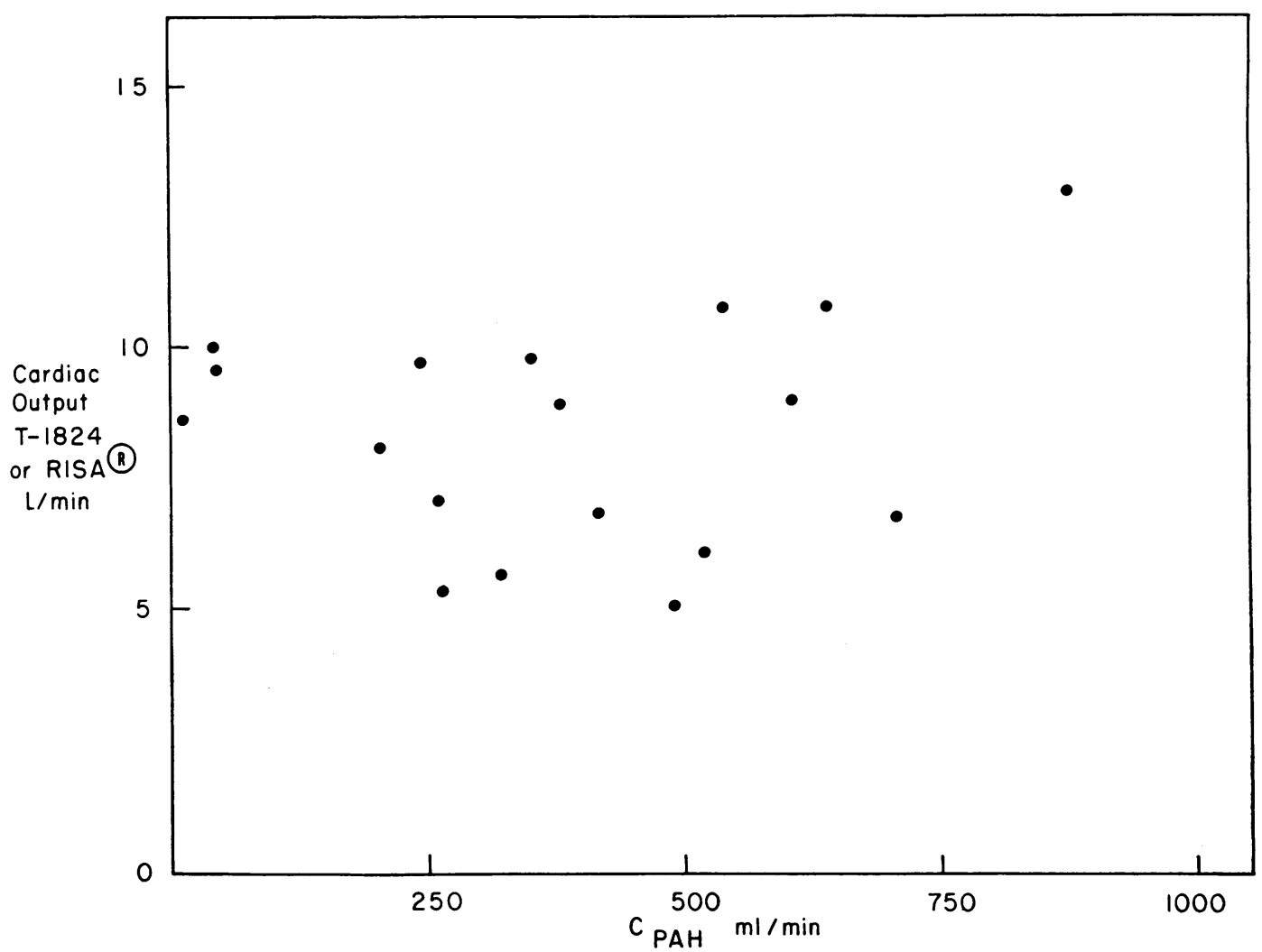

Fig. 2. Cardiac output and para-aminohippurate clearance ( $\mathrm{C}_{\text {pah }}$ ) in patients with decomPENSATEd LAENNEC'S CIRRHosis. Note the coexistence of reduced $\mathrm{C}_{\mathbf{P A B}}$ with elevated cardiac output.

RFCO was also low in these patients and ranged between 6.7 and 13.3 per cent. Elevated $\mathrm{CO}$ was therefore observed among patients who exhibited a broad range of renal hemodynamics (see Figures 1 and 2).

Patient W.F. This patient was studied on two occasions 7 months apart. During his first hospitalization, his $\mathrm{C}_{\mathrm{IN}}$ was $114 \mathrm{ml}$ per minute, $\mathrm{C}_{\mathbf{P A H}}$ $417 \mathrm{ml}$ per minute, and $\mathrm{CO} 6.9 \mathrm{~L}$ per minute (Table II). On his terminal hospital admission, he appeared more severely ill, was more jaundiced, and had a reduction in systemic blood pressure. He had oliguria, his $C_{I N}$ was 9 to $14 \mathrm{ml}$ per minute, $\mathrm{C}_{\mathbf{P A H}} 40$ to $43 \mathrm{ml}$ per minute, and $\mathrm{CO}$ 9.5 to $10.0 \mathrm{~L}$ per minute.

\section{DISCUSSION}

An elevated $\mathrm{CO}$ was observed in patients with a broad range of renal hemodynamics. The findings indicate that the diminished glomerular filtration rate (GFR) and renal plasma flow (RPF) found in some patients with decompensated
Laennec's cirrhosis may occur in the presence of an elevated CO. It is therefore apparent that the reduction in renal perfusion observed in these patients cannot be attributed to a low CO.

$\mathrm{CO}$ has been found elevated in one-third of the patients with cirrhosis studied by Kowalski and Abelmann (17), an observation confirmed by others (18). No correlation has been found between the elevated $\mathrm{CO}$ and the presence of ascites, edema, or jaundice $(17,18)$. Although chronic anemia may be associated with an elevated $\mathrm{CO}$ when the hematocrit falls below 20 per cent (19), anemia of such degree was not observed in these patients and therefore cannot satisfactorily explain the elevation in CO. Since in most instances the mean arterial blood pressure is not elevated, the calculated total vascular peripheral resistance is low (17). Although the precise mechanism producing the reduction in total vascular peripheral resistance and the elevation in $\mathrm{CO}$ is not known, there is evidence suggestive of functional peripheral shunting $(17,18)$. Indeed, the circulation in 
certain patients with cirrhosis partly resembles that in other hyperkinetic states, such as thyrotoxicosis, chronic anemia, beriberi, and those occurring with arteriovenous fistulas $(18,20)$. In these conditions, as well as in the patients of the present study, renal hemodynamics are variable and do not follow a consistent pattern. Indeed, an elevated $\mathrm{CO}$ may occur in the presence of a normal (21-23), reduced (24), and sometimes elevated (25) RPF. The precise relationship between both parameters has been not adequately defined in these conditions. Although this study does not clarify this relationship further, at least three possibilities deserve consideration in patients with cirrhosis and renal failure. First, it is possible that the reduced renal hemodynamics and the elevated $\mathrm{CO}$ are unrelated phenomena. ${ }^{1}$ Second, it is also possible that the same mechanism that produces a decrease in total vascular peripheral resistance and an increase in $\mathrm{CO}$ may also produce a separate, direct effect on the renal circulation. Third, it is conceivable that the decreased renal perfusion in cirrhosis is secondary to a redistribution of blood to areas of decreased resistance. The last possbiility has a counterpart in the experimentally produced acute arteriovenous fistula in the dog. When the fistula was opened, a decrease in RPF occurred (27). Nevertheless, the experimental situation is not entirely comparable, since in the dog GFR varied inconsistently and FF was always elevated (27), whereas in the present study FF varied within a broad range and was not always elevated. Furthermore, Epstein, Post, and McDowell demonstrated in patients with arteriovenous fistulas that occlusion did not produce consistent and significant changes in renal hemodynamics (21).

Since in the present study catheterization of the renal vein was not performed and extraction ratios of the para-aminohippurate were not measured, $\mathrm{C}_{\mathbf{P A H}}$ may underestimate $\mathrm{RPF}$ in patients with reduced renal hemodynamics (28). Indeed, $\mathrm{C}_{\mathrm{PAH}}$ may underestimate the directly measured RPF even if the extraction ratio is determined from analysis of the blood entering and leaving an

1 Although a low CO was not observed in the present study in patients with decreased renal hemodynamics, Tyler, Jeffries, and Wilder recently reported seven patients with cirrhosis and marked reduction in renal blood flow, some of whom have a low CO (26). isolated, perfused kidney (28). The same limitations apply to other parameters derived from $\mathrm{C}_{\mathbf{P A H}}$, e.g., FF, ERBF, and RFCO.

Although the inverse relationship between $\mathrm{CO}$ and renal hemodynamics observed in W.F. (see Table II) is of interest, more observations will be required before it can be interpreted.

\section{SUM MARY}

Cardiac output (CO) and the clearances of inulin $\left(\mathrm{C}_{\mathrm{IN}}\right)$ or endogenous creatinine $\left(\mathrm{C}_{\mathrm{CR}}\right)$ and para-aminohippurate $\left(\mathrm{C}_{\mathbf{P A H}}\right)$ were determined simultaneously in seven patients with decompensated Laennec's cirrhosis and a $\mathrm{C}_{\mathrm{IN}}$ or $\mathrm{C}_{\mathrm{CR}}$ less than $60 \mathrm{ml}$ per minute. Another thirteen decompensated cirrhotics with a $\mathrm{C}_{\mathrm{IN}}$ or $\mathrm{C}_{\mathrm{CR}}$ greater than $70 \mathrm{ml}$ per minute were studied in the same manner. $\mathrm{CO}$ was generally elevated in patients with a broad range of renal hemodynamics. The findings also indicated that the diminished glomerular filtration rate and renal plasma flow found in some patients with cirrhosis may occur in the presence of an increased CO. Therefore, the decreased renal perfusion observed in certain patients with cirrhosis cannot be attributed to a low cardiac output.

\section{ACKNOWLEDGMENTS}

The authors gratefully acknowledge the invaluable assistance of Misses Elsie C. Rossmeisl, Helen C. Alpert, and Rosalie Gardner, and Mmes. Margie P. Homer, Joyce K. Randolph, and Joyce C. Gill.

\section{REFERENCES}

1. Papper, S., Belsky, J. L., and Bleifer, K. H. Renal failure in Laennec's cirrhosis of the liver. I. Description of clinical and laboratory features. Ann. intern. Med. 1959, 51, 759.

2. Hecker, R., and Sherlock, S. Electrolyte and circulatory changes in terminal liver failure. Lancet, 1956, 2, 1121.

3. Papper, S. The role of the kidney in Laennec's cirrhosis of the liver. Medicine, 1958, 37, 299.

4. Nelson, W. P., III, Rosenbaum, J. D., and Strauss, M. B. Hyponatremia in hepatic cirrhosis following paracentesis. J. clin. Invest. 1951, 30, 738.

5. Lancestremere, R. G., Davidson, P. L., Earley, L. E., O'Brien, F. J., and Papper, S. Unpublished observations.

6. Waugh, W. H. Functional types of acute renal failure and their early diagnosis. A.M.A. Arch. intern. Med. 1959, 103, 686.

7. Meroney, W. H., and Rubini, M. E. Kidney function during acute tubular necrosis: Clinical studies and a theory. Metabolism, 1959, 8, 1. 
8. Gornel, D. L., Lancestremere, R. G., Papper, S., and Lowenstein, L. M. Acute changes in renal excretion of water and solute in patients with Laennec's cirrhosis, induced by the administration of the pressor amine, metaraminol. J. clin. Invest., 1962, 41, 594.

9. Bloodworth, J. M. B., Jr., and Sommers, S. C. "Cirrhotic Glomerulosclerosis," a renal lesion associated with hepatic cirrhosis. Lab. Invest. 1959, 8, 962.

10. Smith, H. W. Principles of Renal Physiology. New York, Oxford, 1956, p. 200.

11. Hamilton, W. F., Riley, R. L., Attyah, A. M., Cournand, A., Fowell, D. M., Himmelstein, A., Nobel, R. P., Remington, J. W., Richards, D. W., Jr., Wheeler, N. C., and Witham, A. C. Comparison of the Fick and dye injection methods of measuring the cardiac output in man. Amer. J. Physiol. 1948, 153, 309.

12. Tanner, J. M. Fallacy of per-weight and per-surface area standards, and their relation to spurious correlation. J. appl. Physiol. 1949, $2,1$.

13. Peters, J. H. The determination of creatinine and creatine in blood and urine with the photoelectric colorimeter. J. biol. Chem. 1942, 146, 179.

14. Hare, R. S. Endogenous Creatinine in Serum and Urine. Proc. Soc. Exp. Biol. (N. Y.) 1950, 74, 148.

15. Young, M. K., Jr., and Raisz, L. G. An Anthrone Procedure for Determination of Inulin in Biological Fluids. Proc. Soc. exp. Biol. (N. Y.) 1952, 80, 77.

16. Goldring, W., and Chasis, H. Hypertension and Hypertensive Disease. New York Commonwealth Fund, 1944, p. 203.

17. Kowalski, H. J., and Abelmann, W. H. The cardiac output at rest in Laennec's cirrhosis. J. clin. Invest. $1953,32,1025$.
18. Murray, J. F., Dawson, A. M., and Sherlock, S. Circulatory changes in chronic liver disease. Amer. J. Med. 1958, 24, 358.

19. Brannon, E. S., Merrill, A. J., Warren, J. V., and Stead, E. A., Jr. The cardiac output in patients with chronic anemia as measured by the technique of right atrial catheterization. J. clin. Invest. 1945, $24,332$.

20. Judson, W. E. Cardiovascular renal regulation in the hyperkinetic states. Progr. cardiovasc. Dis. 1961, 4, 65.

21. Epstein, F. H., Post, R. S., and McDowell, M. The effect of an arteriovenous fistula on renal hemodynamics and electrolyte excretion. J. clin. Invest. 1953, 32, 233.

22. Epstein, F. H., Shadle, O. W., Ferguson, T. B., and McDowell, M. E. Cardiac output and intracardiac pressures in patients with arteriovenous fistulas. J. clin. Invest. 1953, 32, 543.

23. Eichna, L. W., Farber, S. J., Berger, A. R., Rader, B., Smith, W. W., and Albert, R. E. Non-cardiac circulatory congestion simulating congestive heart failure. Trans. Ass. Amer. Phycns, 1954, 67, 72.

24. Whitaker, W. Some effects of severe chronic anemia on the circulatory system. Quart. J. Med. 1956, 25, 175.

25. Hlad, C. J., Jr., and Bricker, N. S. Renal function and $\mathrm{I}^{131}$ clearance in hyperthyroidism and myxedema. J. clin. Endocr. 1954, 14, 1539.

26. Tyler, J. M., Jeffries, J. L., and Wilder, C. E. A study of the renal blood flow by nitrous oxide technique in normal and oliguric patients with cirrhosis of the liver. Clin. Res. 1962, 10, 194.

27. Hilton, J. G., Kanter, D. M., Hays, D. R., Bowen, E. H., Golub, J. R., Keating, J. H., and Wégria, R. The effect of acute arteriovenous fistula on renal functions. J. clin. Invest. 1955, 34, 732.

28. Strauss, M. B. The urine remains the same. A.M.A. Arch. intern. Med. 1959, 103, 489. 